\title{
SCIENTIFIC REP

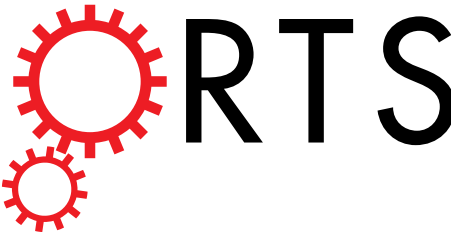 \\ OPEN A route to possible civil engineering materials: the case of high-pressure phases of lime
}

Received: 02 January 2015

Accepted: 26 May 2015

Published: 23 July 2015

\section{A. Bouibes \& A. Zaoui}

Lime system has a chemical composition $\mathrm{CaO}$, which is known as thermodynamically stable. The purpose here is to explore further possible phases under pressure, by means of variable-composition $a b$ initio evolutionary algorithm. The present investigation shows surprisingly new stable compounds of lime. At ambient pressure we predict, in addition to $\mathrm{CaO}, \mathrm{CaO}_{2}$ as new thermodynamically stable compound. The latter goes through two phases transition from $\mathrm{C}_{2} / \mathrm{c}$ space group structure to Pna21 at $1.5 \mathrm{GPa}$, and Pna21 space group structure to $14 / \mathrm{mcm}$ at $23.4 \mathrm{GPa}$. Under increasing pressure, further compounds such as $\mathrm{CaO}_{3}$ become the most stable and stabilize in $\mathrm{P}-42_{1} \mathrm{~m}$ space group structure above $65 \mathrm{GPa}$. For the necessary knowledge of the new predicted compounds, we have computed their mechanical and electronic properties in order to show and to explain the main reasons leading to the structural changes.

Lime is one of the most important and largely used building materials. It is used in several ways in civil engineering. It can be used alone, hydrated and also by mixing it with other civil engineering materials to perform their properties. Lime is basically known thermodynamically stable as a calcium oxide $(\mathrm{CaO})$. It is usually made by the decomposition of materials that contain calcium carbonate by decomposition reaction: $\mathrm{CaCO}_{3}=\mathrm{CaO}+\mathrm{CO}_{2}$. The stability and structural properties of the mineral parent (calcite) has been subject of intense investigations ${ }^{1-4}$. However, less is known about further possible phases of lime.

The goal of the present work is to investigate new thermodynamically stable compounds from lime system. New stable stoichiometries could have, indeed, important planetological and chemical implications.

Calcium oxide, $\mathrm{CaO}$, is one of the most known thermodynamically stable compounds of $\mathrm{Ca}-\mathrm{O}$ system at ambient conditions. This is one of the most abundant compounds in the planetary mantles after $\mathrm{MgO}, \mathrm{SiO}_{2}$ and $\mathrm{FeO}$, which are considered as the building blocks of the mantle minerals 5 . Several experimental and theoretical investigations of high-pressure structure and phase stability of $\mathrm{CaO}$ have been done, resulting that, $\mathrm{CaO}$ crystallizes in the $\mathrm{NaCl}$-type structure (B1) and transforms into CsCl-type structure (B2) around $62 \mathrm{GPa}$. The corresponding ground state properties have been widely investigated both experimentally and theoretically ${ }^{5-7}$.

On the other hand, a recent theoretical study shown that calcium peroxide, $\mathrm{CaO}_{2}$, is a thermodynamically stable composition in $\mathrm{Pna}_{1}$ space group structure at ambient conditions ${ }^{8}$. Mumtaz et al. performed experimentally the structural properties of calcium peroxides. They observed a tetragonal structure for $\mathrm{CaO}_{2}{ }^{9}$. However, apart of this, much is still to be known about its fundamental properties as well as its behavior under pressure effect.

In the present study, we aim to investigate the new thermodynamically stable compounds based on $\mathrm{Ca}-\mathrm{O}$ composition. To this end, we will explore all stable compositions from $\mathrm{Ca}-\mathrm{O}$ system and their crystal structures at high pressures using the variable and fixe composition ab initio evolutionary algorithm ${ }^{10}$. Besides, we will discuss their different structures, phase transitions, elastic properties and chemical bonding.

In order to find all possible phases of lime and their corresponding structures, we used the ab initio evolutionary algorithm (USPEX) $)^{10-12}$, which has a capability to simultaneously find stable stoichiometries

LGCgE, Polytech'Lile, University of Lille1. Cité Scientifique, Avenue Paul Langevin, 59655 Villeneuve d'Ascq, France. Correspondence and requests for materials should be addressed to A.Z. (email: azaoui@polytech-lille.fr) 

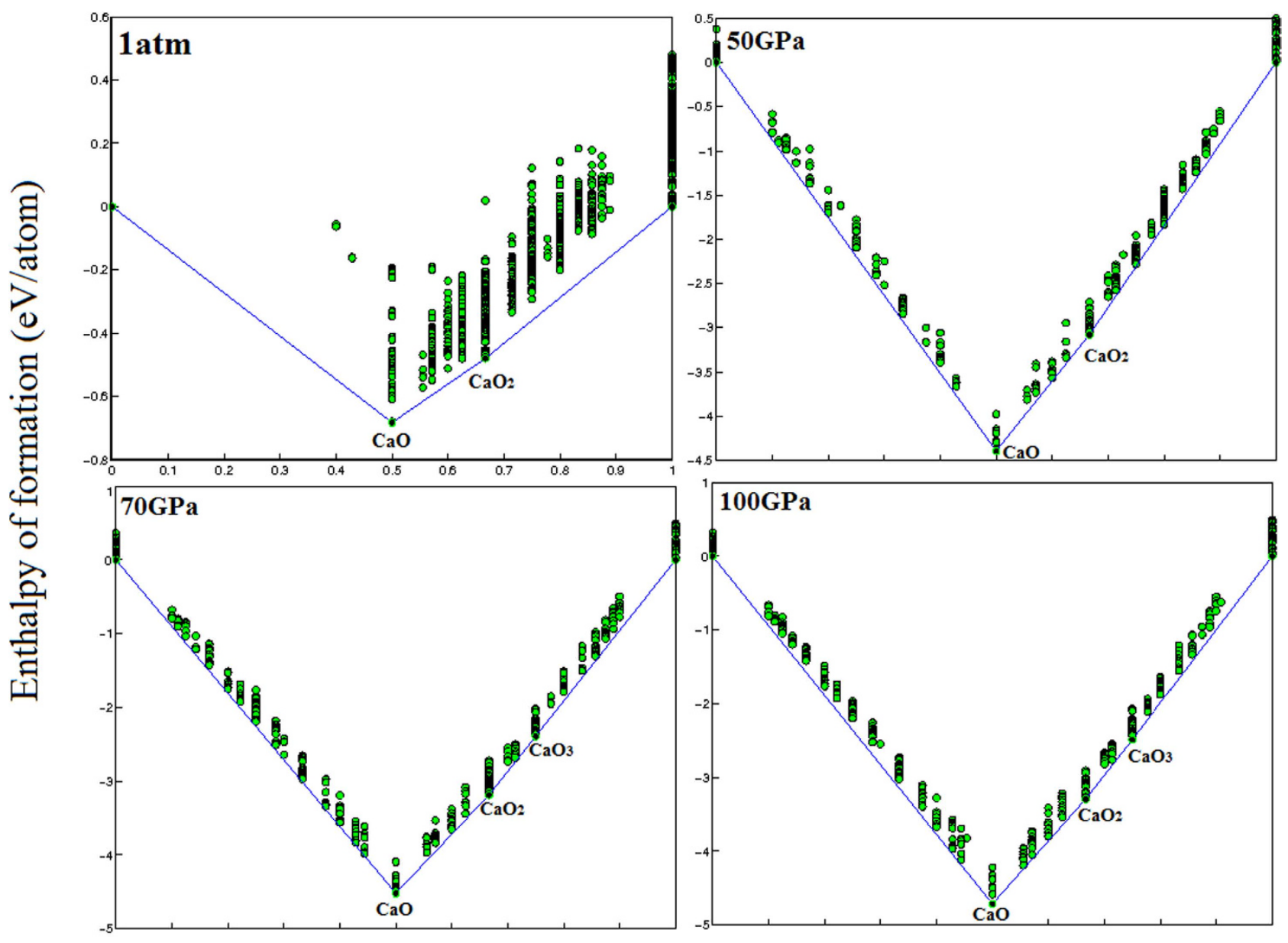

\section{Composition ratio $\mathrm{O} /(\mathrm{Ca}+\mathrm{O})$}

Figure 1. Convex hull diagrams for the $\mathrm{Ca}$ - $\mathrm{O}$ system at different pressure: (a) 1atm; (b) $50 \mathrm{GPa}$, (c) $70 \mathrm{GPa}$ and (d) $100 \mathrm{GPa}$.

and the corresponding structures in multicomponent systems. In our calculations, we allowed all possible compositions in our studied system with structures containing up to 10 atoms in the unit cell. The calculations were performed at zero Kelvin and pressures of $1 \mathrm{~atm}, 50 \mathrm{GPa}, 70 \mathrm{GPa}$ and $100 \mathrm{GPa}$. The initial generation consisted of 120 structures, and all subsequent generations have 40 structures. Stable structures and their compositions were determined using the convex hull construction. A compound is thermodynamically stable if the enthalpy of its decomposition into any other compound is positive ${ }^{10}$.

The present investigation results a surprisingly new stable compounds of lime. While we reproduce stability of $\mathrm{CaO}$ in the whole pressure range investigated here, new stable compounds are predicted. In Fig. 1, we display the convex hull of Ca-O system at high pressure. The enthalpies of formation of the predicted structures are shown as well. It can be clearly seen that in addition to $\mathrm{CaO}, \mathrm{CaO}_{2}$ is thermodynamically stable at high pressure.

At $70 \mathrm{GPa}$, convex hull diagram shows that a new compound, namely $\mathrm{CaO}_{3}$, becomes thermodynamically stable. The latter remains thermodynamically stable up to $100 \mathrm{GPa}$ (Fig. 1). The latter have never been reported before.

Thereafter, we explore all our results of stable compounds for lime, using fixe composition evolution algorithm, in order to determine the possible phase change under pressure. The structure prediction runs for $\mathrm{CaO}$ and $\mathrm{CaO}_{2}$ compound were performed at $1 \mathrm{~atm}, 20 \mathrm{GPa}, 50 \mathrm{GPa}, 70 \mathrm{GPa}$ and $100 \mathrm{GPa}$, for $\mathrm{CaO}_{3}$ at $70 \mathrm{GPa}$, all at zero Kelvin. The phase diagram and crystal structures of the newly predicted compounds are remarkable. The pressure-composition phase diagram is shown in Fig. 2. We may see that $\mathrm{CaO}$ phase transition occurs at around $65 \mathrm{GPa}$. It is stable below $65 \mathrm{GPa}$ in $\mathrm{Fm}-3 \mathrm{~m}$ space group structure. Above $65 \mathrm{GPa}$, the structure of $\mathrm{Pm} 3 \mathrm{~m}$ space group becomes more stable. This is in good agreement with both experimental and theoretical data ${ }^{5-7}$. On the other hand, calcium peroxide, $\mathrm{CaO}_{2}$, stabilize in $\mathrm{C} 2 / \mathrm{c}$ space 


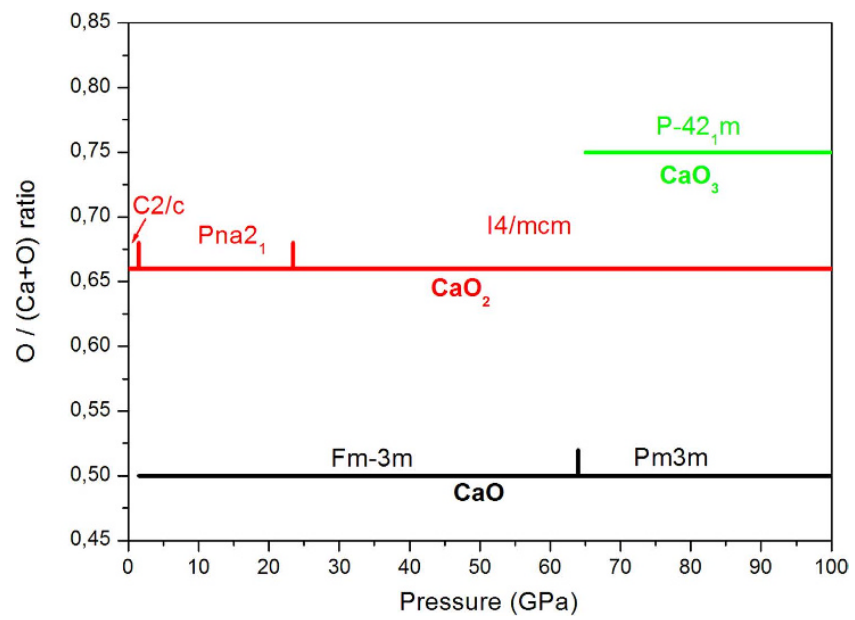

Figure 2. Pressure composition phase diagram of Ca-O system.

group structure (Fig. 3a) at ambient conditions. At $1.5 \mathrm{GPa}, \mathrm{CaO}_{2}$ has a first phase transition. Pna2 space group structure (Fig. $3 \mathrm{~b}$ ), reported by Zhao et al. ${ }^{8}$, becomes the most stable between $1.5 \mathrm{GPa}$ and 23.4 GPa. The second phase transition of $\mathrm{CaO}_{2}$ occurs at $23.4 \mathrm{GPa}$. Above $23.4 \mathrm{GPa}$, a new $\mathrm{I} / \mathrm{mcm}$ structure (Fig. 3c) is predicted to be stable. $\mathrm{CaO}_{3}$ stabilizes in $\mathrm{P}-42_{1} \mathrm{~m}$ space group structure above $65 \mathrm{GPa}$ (Fig. 4). Each $\mathrm{Ca}$ atom is bonded with four series of $\mathrm{O}_{3}$ units, and each oxygen atom is bonded with four atoms of calcium. The structural properties for all these compounds are reported in Table 1.

In order to confirm the stability of the obtained structures at different pressures, we list in Table 2 the enthalpies per formula unit of each compound with the one of oxygen. For instance, the enthalpy of the decomposition reaction $\Delta \mathrm{E}$ of $\mathrm{CaO}_{2}$, from a reaction $\mathrm{CaO}+1 / 2 \mathrm{O}_{2}->\mathrm{CaO}_{2}$, is defined as:

$$
\Delta \mathrm{E}=\mathrm{E}(\mathrm{CaO})+1 / 2 \mathrm{E}\left(\mathrm{O}_{2}\right)-\mathrm{E}\left(\mathrm{CaO}_{2}\right)
$$

$\mathrm{E}(\mathrm{CaO}), \mathrm{E}\left(\mathrm{CaO}_{2}\right)$ and $\mathrm{E}\left(\mathrm{O}_{2}\right)$ are enthalpy per formula unit of the oxide $\mathrm{CaO}, \mathrm{CaO}_{2}$ and isolated oxygen molecule. Positive reaction enthalpy indicates a thermodynamically stable compound. Furthermore, a compound is thermodynamically stable if the enthalpy of its decomposition into any other compounds is positive. A compound is thermodynamically stable if the enthalpy of its decomposition into any other compounds is positive. Indeed at $1 \mathrm{~atm}$, we obtain $\mathrm{E}(\mathrm{CaO})=-12.95 \mathrm{eV}$ per f.u. and $\mathrm{E}\left(\mathrm{O}_{2}\right)=-9.94 \mathrm{eV}$ per molecule. The decomposition energy $\Delta \mathrm{E}$ of the $\mathrm{CaO}_{3}$ is $-0.69 \mathrm{eV}$, indicating that it is not stable at ambient pressure.

Mechanically, the elastic constants of a material describe its response to an applied stress or, conversely, the stress required to maintain a given deformation. These properties are obviously directly related to the mechanical stability of a given system. The criteria of the mechanical stability of a monoclinic crystal are as follows ${ }^{13}$ :

$$
\mathrm{K}_{2}=\operatorname{det}\left(\mathrm{C}_{\mathrm{ij}}\right), \mathrm{i}, \mathrm{j}<5, \quad \mathrm{~K}_{2}>0, \quad \mathrm{C}_{44} \mathrm{C}_{66}-\mathrm{C}_{46}{ }^{2}>0
$$

and of tetragonal crystal are ${ }^{13}$ :

$$
\mathrm{C}_{44}>0, \mathrm{C}_{66}>0, \mathrm{C}_{11}-\mathrm{C}_{12}>0, \quad\left(\mathrm{C}_{11}+\mathrm{C}_{12}\right) \mathrm{C}_{33}-2 \mathrm{C}_{13}^{2}>0
$$

The calculated elastic constants of $\mathrm{CaO}_{2}, \mathrm{CaO}_{3}$, at 1atm, $65 \mathrm{GPa}$ respectively are listed in Table 3 . The above mentioned criteria are satisfied in our case, indicating that $\mathrm{CaO}_{2}, \mathrm{CaO}_{3}$ are mechanically stable at the corresponding conditions. For comparison, the values of the elastic properties of $\mathrm{CaO}$ are presented as well, and we notice the excellent agreement with the reported data. We may also underline that calcium oxide is more rigid and more resistant to shear deformation than calcium peroxide at the ambient conditions. Moreover, the Pugh modulus ratio ${ }^{14} k=\mathrm{G} / \mathrm{B}$ is also reported in Table 3 to show the ductile-brittle behavior of high pressure lime phases. For brittle materials, G/B is higher than 0.571, whereas, for the ductile ones, it is lower than 0.571. It follows that $\mathrm{CaO}$ and $\mathrm{CaO}_{3}$ are brittle; while $\mathrm{CaO}_{2}$ is ductile. According to the following equation of hardness ${ }^{15}$ :

$$
\mathrm{H}=2^{*}\left(k^{2} \mathrm{G}\right)^{0.585}-3
$$

The Vickers hardness $\mathrm{H}$ of $\mathrm{CaO}, \mathrm{CaO}_{2}$, and $\mathrm{CaO}_{3}$ are $13.75,4.28$ and $16.88 \mathrm{GPa}$ respectively, suggesting that the harder phase is $\mathrm{CaO}_{3}$ and the less hard is $\mathrm{CaO}_{2}$. 


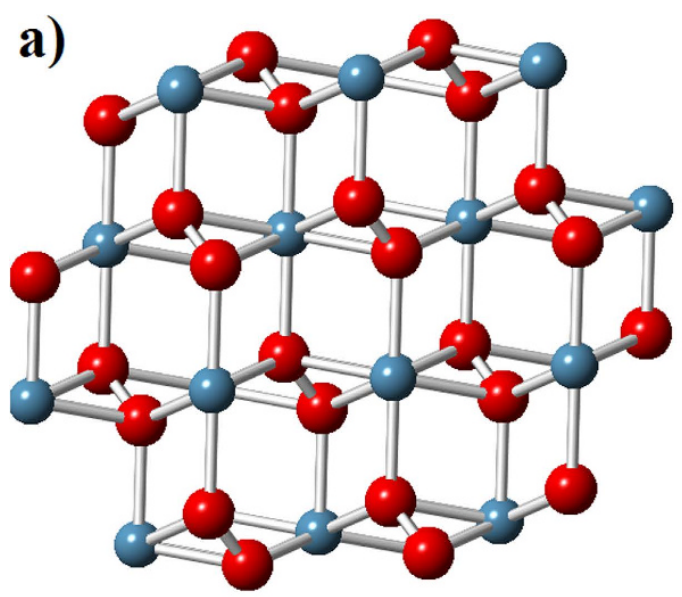

b)

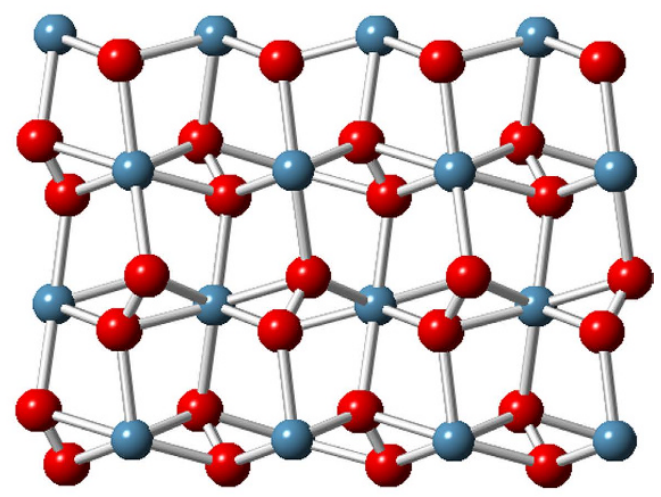

c)

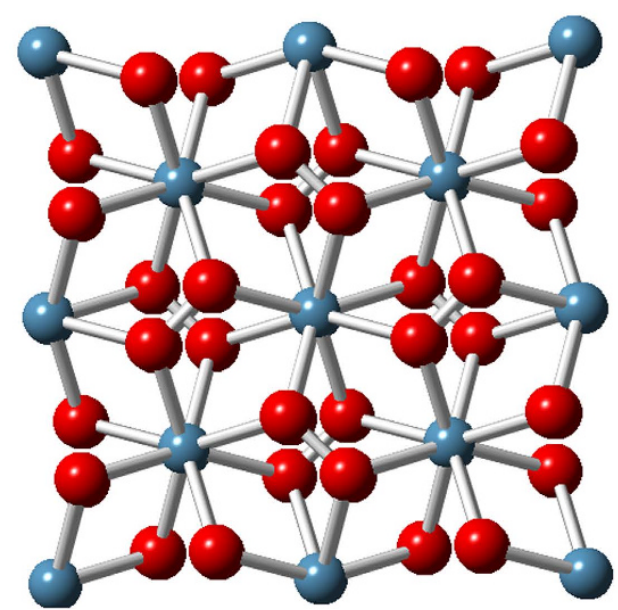

Figure 3. $\mathrm{CaO}_{2}$ structures: $\left(\right.$ a) $\mathrm{CaO}_{2}-\mathrm{C} 2 / \mathrm{c}$ (b) $\mathrm{CaO} 2-\mathrm{Pna}_{1}$ (c) $\mathrm{CaO}_{2}-\mathrm{I} 4 / \mathrm{mcm}$. Large blue spheres $-\mathrm{Ca}$ atoms, small red spheres $-\mathrm{O}$ atoms.

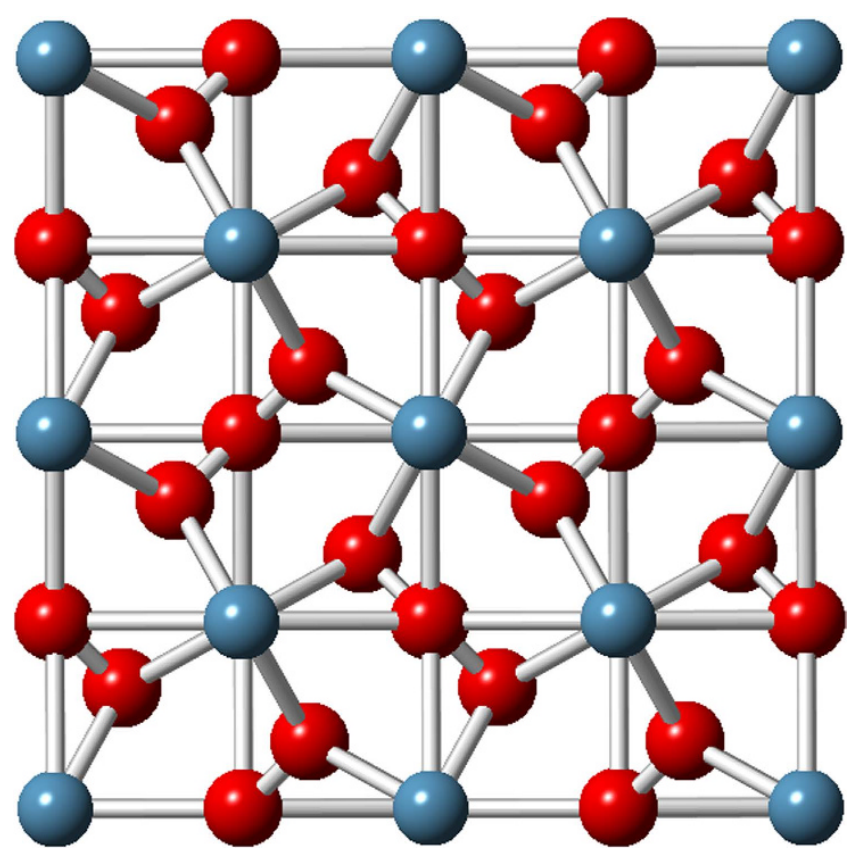

Figure 4. Crystal structure $\mathrm{CaO}_{3}$. Large blue spheres - Ca atoms, small red spheres - O atoms. 


\begin{tabular}{|c|c|c|c|c|c|c|}
\hline Structure & Space group & $\begin{array}{l}\text { Lattice Parameters } \\
(\AA)\end{array}$ & & $\mathbf{x}$ & $\mathbf{Y}$ & $\mathrm{Z}$ \\
\hline \multirow[t]{2}{*}{ CaO-Phasel } & $\mathrm{Fm}-3 \mathrm{~m}$ & $\mathrm{a}=4.8$ & $\mathrm{Ca}$ & 0.00 & 0.00 & 0.00 \\
\hline & & & $\mathrm{O}$ & 0.50 & 0.00 & 0.00 \\
\hline \multirow[t]{2}{*}{ CaO-Phase2 } & $\mathrm{Pm} 3 \mathrm{~m}$ & $\mathrm{a}=2.56$ & $\mathrm{Ca}$ & 0.00 & 0.00 & 0.00 \\
\hline & & & $\mathrm{O}$ & 0.50 & 0.50 & 0.50 \\
\hline \multirow[t]{4}{*}{$\mathrm{CaO}_{2}$-Phase 1} & $\mathrm{C} 2 / \mathrm{c}$ & $\mathrm{a}=6.82$ & $\mathrm{Ca}$ & 0.5 & 0.14 & 0.75 \\
\hline & & $\mathrm{b}=3.68$ & $\mathrm{O}$ & 0.75 & 0.64 & 0.91 \\
\hline & & $c=7.04$ & & & & \\
\hline & & $\beta=117.9^{\circ}$ & & & & \\
\hline \multirow[t]{2}{*}{$\mathrm{CaO}_{2}$-Phase 3} & $\mathrm{I} 4 / \mathrm{mcm}$ & $a=4.78$ & $\mathrm{Ca}$ & 0.00 & 0.00 & 0.75 \\
\hline & & $c=6.15$ & $\mathrm{O}$ & 0.11 & 0.39 & 0.50 \\
\hline \multirow[t]{3}{*}{$\mathrm{CaO}_{3}$} & $\mathrm{P}-42_{1} \mathrm{~m}$ & $a=4.68$ & $\mathrm{Ca}$ & 0.00 & 0.00 & 0.00 \\
\hline & & $c=2.84$ & $\mathrm{O} 1$ & 0.00 & 0.50 & 0.79 \\
\hline & & & $\mathrm{O} 2$ & 0.82 & 0.32 & 0.51 \\
\hline
\end{tabular}

Table 1. Structural properties and entropy of stable phases of lime.

\begin{tabular}{|l|c|c|c|c|}
\hline & $\mathbf{E}\left(\mathbf{O}_{2}\right)$ & $\mathrm{E}(\mathrm{CaO})$ & $\mathbf{E}\left(\mathrm{CaO}_{2}\right)$ & $\mathbf{E}\left(\mathrm{CaO}_{3}\right)$ \\
\hline $1 a t m$ & -9.94 & -12.95 & -17.96 & -22.20 \\
\hline $50 G P a$ & -4.52 & -5.38 & -8.09 & -10.25 \\
\hline $70 G P a$ & -2.85 & -2.83 & -4.78 & -6.46 \\
\hline $100 G P a$ & -0.51 & 0.48 & -0.12 & -0.81 \\
\hline
\end{tabular}

Table 2. Enthalpy of formation (eV) of lime phases at various pressure.

\begin{tabular}{|l|c|c|c|c|}
\hline & \multicolumn{2}{|c|}{$\mathrm{CaO}$} & $\mathrm{CaO}_{2}$ & $\mathrm{CaO}_{3}$ \\
\cline { 2 - 5 } & Fm-3m & Theory-Experiment & $\mathbf{C 2 c}$ & $\boldsymbol{P}^{-42}{ }_{1} \boldsymbol{m}$ \\
\hline $\mathrm{C}_{11}$ & 204.92 & $200^{\mathrm{a}}-221.89^{\mathrm{b}}$ & 151.38 & 442.31 \\
\hline $\mathrm{C}_{22}$ & 206.51 & - & 136.95 & 442.90 \\
\hline $\mathrm{C}_{33}$ & 206.49 & - & 133.35 & 454.63 \\
\hline $\mathrm{C}_{44}$ & 74.68 & $66^{\mathrm{a}}-80.59^{\mathrm{b}}$ & 38.83 & 226.16 \\
\hline $\mathrm{C}_{55}$ & 74.78 & - & 58.73 & 176.29 \\
\hline $\mathrm{C}_{66}$ & 74.78 & - & 53.49 & 174.29 \\
\hline $\mathrm{C}_{12}$ & 54.07 & $50^{\mathrm{a}}-57.81^{\mathrm{b}}$ & 56.80 & 219.08 \\
\hline $\mathrm{C}_{13}$ & 53.91 & - & 69.89 & 177.54 \\
\hline $\mathrm{C}_{23}$ & 54.86 & - & 54.53 & 177.91 \\
\hline $\mathrm{C}_{46}$ & -0.003 & & 0.35 & 0.11 \\
\hline $\mathrm{B}$ & 104.46 & $102^{\mathrm{a}}-110^{\mathrm{b}}$ & 92.14 & 276.40 \\
\hline $\mathrm{G}$ & 75.04 & $71^{\mathrm{a}}-80.59^{\mathrm{b}}$ & 43.03 & 184.68 \\
\hline$k=\mathrm{G} / \mathrm{B}$ & 0.71 & & 0.46 & 0.67 \\
\hline $\mathrm{H}$ & 13.75 & & 4.28 & 16.88 \\
\hline
\end{tabular}

Table 3. Mechanical properties of lime phases in GPa units. ${ }^{a}$ Theory ${ }^{14}$, ${ }^{b}$ Experiment $^{13}$.

In order to better understand the bonding behaviors, a Bader charge analysis ${ }^{16}$ of the calculated charge densities is carried out. At ambient pressure, Bader charge analysis shows that each $\mathrm{Ca}$ atom gives 1.47 electrons to each $\mathrm{O}$ atom in $\mathrm{CaO}$. In the case of $\mathrm{CaO}_{2}, \mathrm{Ca}$ atom gives 1.56 electron/atom and $\mathrm{O}$ atom gets -0.78 electron/atom. At $65 \mathrm{GPa}$, the charge configuration of $\mathrm{CaO}_{3}$ is $\mathrm{Ca}^{+1.47}\left[\mathrm{O}^{-0.62} \mathrm{O}^{-0.23} \mathrm{O}^{-0.62}\right]$, the partial electronic charge transfer is not symmetric from the $\mathrm{Ca}$ to $\mathrm{O}$ atoms. We can also notice that the electronic charge of $\mathrm{Ca}$ atom is approximately the same for all phases. Besides, we have performed the total density of state for all stable phases of lime, as represented in Fig. 5. For comparison, we calculate 


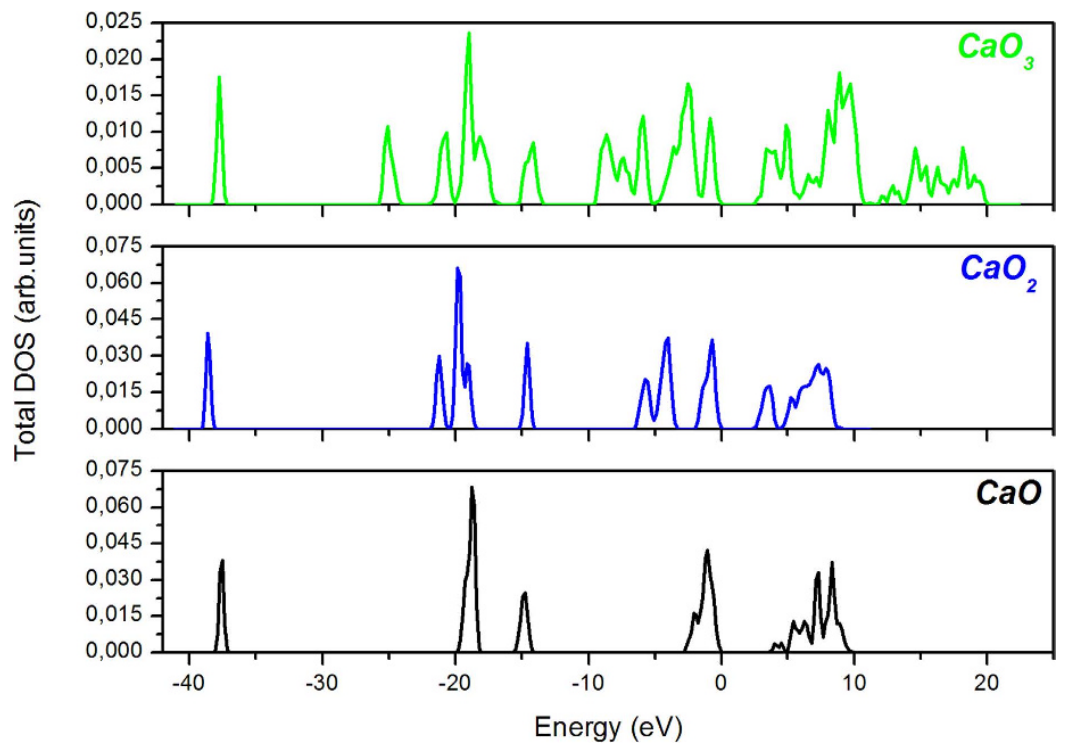

Figure 5. Total DOS for each phase of $\mathrm{Ca}-\mathrm{O}$ for various compositions. The Fermi level is set to zero.

\begin{tabular}{|l|c|c|}
\hline & $\mathbf{C} 2 / c-\mathrm{CaO}_{2}$ & $\mathrm{Pna}_{1}-\mathrm{CaO}_{2}$ \\
\hline $\mathrm{Ca}-\mathrm{O}$ & $2.41 ; 2.42$ & $2.38 ; 2.44 ; 2.42 ; 2.43 ; 2.47$ \\
\hline $\mathrm{O}-\mathrm{O}$ & 1.51 & 1.51 \\
\hline $\mathrm{Ca}-\mathrm{Ca}$ & $3.66 ; 3.67$ & $3.62 ; 3.64$ \\
\hline
\end{tabular}

Table 4. Atomic distance at ambient conditions for $\mathrm{C2} / \mathrm{c}-\mathrm{CaO}_{2}$ structure and $\mathrm{Pna2}_{1}-\mathrm{CaO}_{2}$ structure.

the band gap value of $\mathrm{CaO}(3.65 \mathrm{eV})$, which is in perfect agreement with previous work ${ }^{7}$. The obtained band gap value of $\mathrm{CaO}_{2}, \mathrm{CaO}_{3}$ is $2.78 \mathrm{eV}$ and $2.48 \mathrm{eV}$ respectively. Additionally, magnetic calculation is performed for $\mathrm{CaO}_{3}$ compound. The calculation shows that there is no magnetic moment on all atoms of this compound, what means that $\mathrm{CaO}_{3}$ is non-magnetic.

In the studied pressure range, calcium peroxide knows two phase transitions at $1.5 \mathrm{GPa}$ and at 23.4 GPa. The most stable $\mathrm{CaO}_{2}$ at ambient conditions corresponds to the space group $\mathrm{C} 2 / \mathrm{c}$. Zhao et al. found that $\mathrm{CaO}_{2}$ stabilizes in Pna2 $2_{1}$ space group structure ${ }^{8}$. However, the last structure becomes stable above $1.5 \mathrm{GPa}$ of pressure. After duplicating both structures, we may notice that those structures are very similar as shown in Fig. 2. In Table 4, we compare the atomic distances between the obtained structure and the one of Zhao. We can see that the atomic distances are very close.

Calcium peroxide goes through a second phase transition from Pna2 1 space group structure (Fig. $3 \mathrm{~b}$ ) to $\mathrm{I} / \mathrm{mcm}$ space group structure (Fig. $3 \mathrm{c}$ ) at $23.4 \mathrm{GPa}$. The tetragonal structure with unit cell parameters $\mathrm{a}=5.01 \AA$ and $\mathrm{c}=5.92 \AA$ is observed experimentally at a temperature of $550{ }^{\circ} \mathrm{C}(823 \mathrm{~K})$ by Mumtaz et $a .^{9}$. The corresponding lattice parameters are very similar with our findings. Additionally, we notice that the discovered $\mathrm{MgO}_{2}$ stabilizes also in the same structure with $\mathrm{I} / \mathrm{mcm}$ space group structure above $500 \mathrm{GPa}^{17}$.

In order to understand the main reasons behind $\mathrm{CaO}_{2}$ phase transition, let us analyze in the bonding character through the electronic charge density. Figure 6 represents the electronic charge density of $\mathrm{CaO}_{2}$ compound at $1 \mathrm{~atm}$ and $20 \mathrm{GPa}$ in the $\left(\begin{array}{lll}1 & 1 & 1\end{array}\right)$ plane, which contain the maximum $\mathrm{Ca}$ and $\mathrm{O}$ atoms. We can remark that the electronic structure change between 1atm and $20 \mathrm{GPa}$. Consequently, new bond between calcium and oxygen are formed at 20GPa leading to a new phase. This explains and justifies the main reasons behind the transitions.

In summary, we have explored new phases of lime through variable-composition ab initio evolutionary algorithm. At ambient pressure we predicted, in addition to $\mathrm{CaO}, \mathrm{CaO}_{2}$ as new thermodynamically stable compound under two transitions at $1.5 \mathrm{GPa}$ and at $23.4 \mathrm{GPa}$. Further compounds have been predicted such as $\mathrm{CaO}_{3}$ above $65 \mathrm{GPa}$.

For the more complete knowledge on the new predicted compounds, we have investigated various kinds of properties including mechanical, electronic and bonding to explain the main reasons leading to the transitions giving the new class of materials from the simple lime system. 


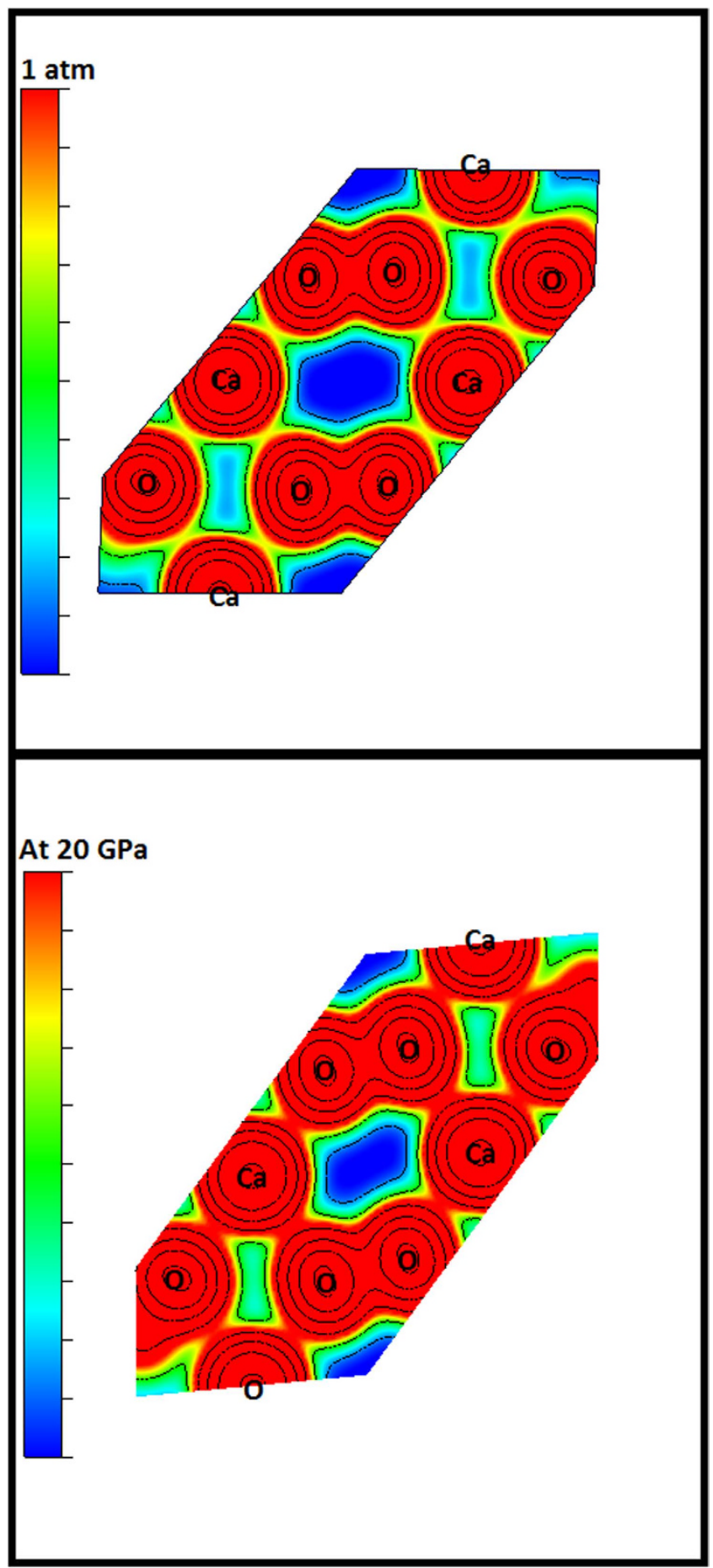

Figure 6. Valence charge density of $\mathrm{CaO}_{2}$-Phasel along the (lll 11 1) plane at 1atm and $20 \mathrm{GPa}$.

\section{Methods summary}

We use here the "Universal Structure Predictor: Evolutionary Xtallography" (USPEX) code ${ }^{10-12}$. The latter is based on approach features global optimization with real-space representation and physically motivated variation operators. To generate every candidate structure, we use first-principles structural relaxation, based on density functional theory within the GGA functional ${ }^{17}$ for solids ${ }^{18,19}$.

We used the projector-augmented wave (PAW) ${ }^{20}$ with $\mathrm{Ca}\left[3 \mathrm{~s}^{2} 3 \mathrm{p}^{6} 4 \mathrm{~s}^{2}\right]$ and $\mathrm{O}\left[2 \mathrm{~s}^{2} 2 \mathrm{p}^{4}\right]$ cores (core radii 2.00 a.u. and 1.5 a.u., respectively). The plane-wave kinetic-energy cutoff is $600 \mathrm{eV}$, and the k-point mesh resolution in reciprocal space is $2 * 0.06 \mathrm{~A}^{-1}$. These settings enable excellent convergences of the energy differences, stress tensors, and structural parameters. The predicted structure calculation was performed with fixed composition. The plane-wave kinetic-energy cutoff is also $600 \mathrm{eV}$, and the k-point mesh resolution in reciprocal space is $2 * 0.03 \mathrm{~A}^{-1}$. 


\section{References}

1. Oganov, A. R. et al. Novel high-pressure structures of $\mathrm{MgCO}_{3}, \mathrm{CaCO}_{3}$ and $\mathrm{CO}_{2}$ and their role in Earth's lower mantle. Earth and Planetary Science Letters 273, 38-47 (2008).

2. Ayoub, A. et al. High-pressure structural phase transitions and mechanical properties of calcite rock. Comp. Mater. Sci. 50, 852-857 (2011).

3. Bouibes, A. \& Zaoui, A. High-pressure polymorphs of $\mathrm{ZnCO}_{3}$ : Evolutionary crystal structure prediction. Nature-Scientific Reports 4, $5172(2014)$

4. Zaoui, A. \& Shahrour, I. Molecular dynamics study of high-pressure polymorphs of $\mathrm{BaCO}_{3}$. Phil. Mag. Lett. 90, 689-697 (2010).

5. Deng, Y. et al. Phase transition and elastic constants of $\mathrm{CaO}$ from first-principle calculations. Physica B: Condens. Matter 392. 229-232 (2007).

6. Richer, P. et al. Static compression and equation of state of $\mathrm{CaO}$ to $1.35 \mathrm{Mbar}$ J. Geophys. Res. 93, 279-288 (1988).

7. Ghebouli, B. et al. First-principles calculations of structural, elastic, electronic and optical properties of $\mathrm{XO}(\mathrm{X}=\mathrm{Ca}, \mathrm{Sr}$ and $\mathrm{Ba})$ compounds under pressure effect. Mater. Sci. Semicond. Process. 13, 92-101 (2010).

8. Zhao, X. et al. Structures and stabilities of alkaline earth metal peroxides $\mathrm{XO}_{2}(\mathrm{X}=\mathrm{Ca}, \mathrm{Be}, \mathrm{Mg})$ studied by a genetic algorithm. RSC Adv. 3, 22135-22139 (2013).

9. Mumtaz, M. et al. Dielectric properties of $\left(\mathrm{CuO}, \mathrm{CaO}_{2} \text {, and } \mathrm{BaO}\right)_{\mathrm{v}} / \mathrm{CuTl}-1223$ composites. J. Low. Temp. Phys. 39, 622-629 (2013).

10. Oganov, A. R. et al. Evolutionary crystal structure prediction as a method for the discovery of minerals and materials. Rev. Mineral Geochem. 71, 271-298 (2010).

11. Oganov, A. R. \& Glass, C. W. Crystal prediction using ab initio evolutionary techniques: Principles and applications. J. Chem. Phys. 124, 244704 (2006)

12. Oganov, A. R. et al. How evolutionary crystal structure prediction works - and why. Acc. Chem. Res. 44, 227-237 (2011).

13. Cowley, R. A. Acoustic phonon instabilities and structural phase transitions. Phys. Rev. B 13, 4877 (1976).

14. Pugh, S. F. X. C. I. I. Relations between the elastic moduli and the plastic properties of polycrystalline pure metals. Philos. Mag. 45, 823-843 (1954).

15. Chen, X. et al. Modeling hardness of polycrystalline materials and bulk metallic glasses. Intermetallics 19, 1275-1281(2011).

16. Bader, R. Atoms in Molecules: A Quantum Theory: Oxford University Press, New York, 1990.

17. Zhu, Q., Oganov, A. R. \& Lyakhov, A. O. Novel stable compounds in the $\mathrm{Mg}-\mathrm{O}$ system under high pressure. Phys. Chem. Chem. Phys 15, 7796-7700 (2013).

18. Perdew, J. P. et al. Generalized gradient approximation made simple. Phys. Rev lett. 77, 3865 (1996).

19. Kresse, G. \& Furthmüller, J. Efficient iterative schemes for $a b$ initio total-energy calculations using a plane-wave basis set. Phys. Rev. B 54, 11169 (1996).

20. Kresse, G. \& Joubert, D. From ultrasoft pseudopotentials to the projector augmented-wave method. Phys. Rev. B 59, 1758 (1999).

\section{Author Contributions}

A.Z. conceived and designed the study. A.B. performed the theoretical studies and simulations. A.B. and A.Z. analyzed and discussed the results. A.B. and A.Z. wrote the manuscript. All authors discussed the conceptual and practical implications of the method at all stages.

\section{Additional Information}

Competing financial interests: The authors declare no competing financial interests.

How to cite this article: Bouibes, A. and Zaoui, A. A route to possible civil engineering materials: the case of high-pressure phases of lime. Sci. Rep. 5, 12330; doi: 10.1038/srep12330 (2015).

(c) (i) This work is licensed under a Creative Commons Attribution 4.0 International License. The images or other third party material in this article are included in the article's Creative Commons license, unless indicated otherwise in the credit line; if the material is not included under the Creative Commons license, users will need to obtain permission from the license holder to reproduce the material. To view a copy of this license, visit http://creativecommons.org/licenses/by/4.0/ 